\title{
Prevalence of oral lesions in HIV infected adult population of Mangalore, Karnataka, India
}

\author{
Mithra N. Hegde ${ }^{1 *}$, Nidarsh D. Hegde ${ }^{2}$, Amit Malhotra ${ }^{1}$
} ${ }^{1}$ Department of Conservative Dentistry and Endodontics, A. B. Shetty Memorial Institute of Dental Sciences, NITTE University, Derelakatte,
Mangalore, India
${ }^{2}$ Department of Oral and Maxillofacial Surgery, A. B. Shetty Memorial Institute of Dental Sciences, NITTE University, Derelakatte, Mangalore,
India

\begin{abstract}
The aim of this study was to find the prevalence of oral lesions in human immunodeficiency virus (HIV) positive patients and investigate if there was a relationship between oral manifestations and the level of immunosuppression. 125 patients infected with HIV in the age group of 20-40 years were examined for the presence of different oral lesions according to the EEC criterion. The CD4 count, as well as any therapy being instituted was recorded and correlated with the oral manifestations seen. Comparison of common oral lesions present to absent was done by chi square test using linear by linear association. The prevalence of oral lesions among the investigated HIV patients was found to be $71 \%$, with periodontitis $-52 \%$ and erythematous candidiasis $-48 \%$ being the most prevalent oral lesions; as well, periodontitis and oral hairy leukoplakia were found to be significantly associated with the immunosuppression in the disease. Thus, oral lesions have been found to be associated with the early manifestation of HIV and a measure of disease severity.
\end{abstract}

Citation: Hegde MN, Hegde ND, Malhotra A. Prevalence of oral lesions in HIV infected adult population of Mangalore, Karnataka, India. BioDiscovery 2012; 4: 3; DOI: 10.7750/BioDiscovery.2012.4.3

Copyright: (C) 2012 Hegde et al. This is an open-access article distributed under the terms of the Creative Commons Attribution License, which permits unrestricted use, provided the original authors and source are credited.

Received: 23 July 2012; Revised: 10 October 2012; Accepted: 17 October 2012; Available online/Published: 23 October 2012

Keywords: HIV, CD4 count, Immunosuppression, Oral lesions.

"Corresponding Author: Mithra Hegde, e-mail: drhegdedentist@gmail.com

Conflict of Interests: No potential conflict of interest was disclosed by any of the authors.

\section{Introduction}

Human immunodeficiency virus (HIV) disease affects the entire body. Any health personnel dealing with diagnosis and treatment in humans is at risk to get infected with this dreaded disease if proper preventive guidelines are not followed. Thus it becomes imperative to be aware of the various forms of HIV manifestations.

Oral health is an important component of the overall health status in HIV infection. Awareness of the variety of oral disorders which can develop throughout the course of HIV infection and coordination of health care services between a physician and a dentist may improve the overall health of the patient. The HIV infection progresses to acquired immunodeficiency syndrome AIDS [1].

AIDS epidemic is increasing all over the world without any definite treatment. Antiretroviral medications can only control the progression rate of disease [2-4]. Oral manifestations of HIV infection are important in the AIDS epidemic and some of them could be used to assess the status of immune-suppression and determine the prognosis of the disease [5]. Some oral lesions may even 
affect patient's quality of life [6]. Early diagnosis and appropriate treatment of oral lesions have great influence on patients' general health and can reduce the mortality rate of the disease [7]. Reduction of circulating CD4 count is the main criteria for assessing the immunosuppression status in HIV-positive patients. The normal number of circulating CD4 cells ranges from 600 to 1600 cells/ $\mathrm{mm}^{3}$, but the initial signs of immunosuppression occur when CD4 count is lower than 500 cells $/ \mathrm{mm}^{3}$. WHO proposed the immunological classification on the basis of CD4 count as none or not significant - Group 1 ( $>500 /$ $\mathrm{ml})$, mild - Group 2 (350-499/ml), advanced - Group 3 $(200-349 / \mathrm{ml})$ and severe - Group $4(<200 / \mathrm{ml})$. Studying the prevalence of AIDS-related oral lesions in different regions of the world is important as it provides a more thorough description of the epidemic and scientific basis for the appropriate management of the disease by health care workers [8]. Although some lesions such as candidiasis and hairy leukoplakia are considered as prognostic factor of HIV disease, recent data have indicated that concurrent existence of multiple and variable oral lesions is accompanied with poor prognosis of the disease [9].

Santos et al. reported that oral lesions were common among HIV positive children and the most common lesion was pseudomembranous candidiasis. Most of the patients with oral candidiasis were suffering from severe immunosuppression, and they concluded that candidiasis and gingivitis could be considered as an indicator of the disease progression [4]. The research work conducted by Sud et al. and Nokta have also shown an association between low CD4 counts and candidiasis, linear gingival erythema, angular cheilitis, scabies, paronychia, oral pigmentation, diffuse hair loss and other oral symptoms $[7,8]$.

Since the oral manifestations of HIV infection are common and can be considered as indicators of immunosuppression, the aim of this survey was to investigate if there was a relationship between oral manifestations and the level of immunosuppression in HIV-positive patients. The results might be used as a guide in determining the immunosuppression level of HIV disease according to oral manifestations.

\section{Materials and Methods}

A cross-sectional study was carried out among 125 proven HIV-positive patients showing positive ELISA and Western blot test, selected randomly from the ART centre, Wenlock Hospital, Mangalore, India. Ethical clearance was obtained from the Institutional Ethical Committee of A.B. Shetty Dental College, Nitte University. Patients were informed about the objective of the study and signed an informed consent form before oral examination.
Data including sexual habits, IV drug abuse, hemophilia, blood transfusion, addiction, other diseases, previous CD4 counts, and opportunistic systemic infections were extracted from the patient records. All patients received oral hygiene instructions. CD4 counts were determined using complete blood count and flow cytometry.

A questionnaire was completed for each patient regarding past medical history, systemic signs and symptoms, and oral manifestations. Patients were examined by an infectious disease specialist prior to dental examination. Oral cavity was inspected carefully. Intra-oral examination was performed on a dental unit using disposable dental mirrors and sterile gauze pads under appropriate lighting. Submandibular, submental and cervical lymph nodes were palpated bidigitally by the examiner. Further clinical examination using an explorer and probing with a periodontal probe were done in order to diagnose periodontal diseases. All patients were examined by similar instruments, under the same circumstances and at the same place by the single specialist to avoid the inter-examiner bias.

The oral lesions were diagnosed according to the criteria established by the EC Clearinghouse and WHO (EC Clearinghouse,1993), as follows:

\section{Oral candidiasis}

Shiny erythematous areas of mucosa, sometimes with white patches interspersed. The four clinical subtypes are characterized as:

(1) Erythematous type: red area without removable white spots or plaques.

(2) Pseudomembranous type: white removable spots or plaques.

(3) Hyperplastic type: firm, adherent, unscrapable white plaques.

(4) Angular cheilitis: fiery red commissures with a fissuring or cracking appearance.

\section{Oral hairy leukoplakia (OHL)}

Non-scrapable, corrugated white plaques that did not respond to anti-fungal therapy. These were always on the lateral borders of the tongue.

\section{Gingivitis}

Distinctive dusky red, cyanosed free gingiva, presence of bleeding on probing and/or spontaneous bleeding.

\section{HIV-gingivitis (Linear gingival erythema)}

Gingiva which presents an unusual clinical appearance, such as fiery red band along the margin of the gingiva, with or without focal enlargement of the gingiva in an otherwise healthy oral cavity. No ulceration present, nor pockets or loss of attachment. 


\section{Periodontitis}

Presence of pockets $>4 \mathrm{~mm}$ in one or more sites. All teeth present were probed around the whole circumference with a blunt periodontal probe, with William's markings.

\section{Oral (melanin) pigmentation}

Brown/brownish-black, spotty/diffuse macules, usually occupy areas greater than $1 \mathrm{~cm}$ and asymmetrical in distribution. The level of immunosuppression in each patient was classified according to WHO immunologic staging (Table 1).

Table 1. WHO immunological classification system.

\begin{tabular}{lc}
\hline $\begin{array}{c}\text { HIV - associated } \\
\text { immunodeficiency }\end{array}$ & $\begin{array}{c}\text { CD4 count } \\
\left(\text { cells/ } \mathbf{m m}^{\mathbf{3}}\right)\end{array}$ \\
\hline None or not significant & $>500$ \\
Mild & $350-499$ \\
Advanced & $200-349$ \\
Severe & $<200$ \\
\hline
\end{tabular}

\section{Data collection and statistical analysis:}

The data was recorded and the presence of each lesion was noted, the information collected was then divided into four groups on the basis of immunological classification of WHO. This was a cross-sectional study and point prevalence of each lesion was calculated. Since the nature of data congregated was categorical, chi square test was used to find the relationship between the four groups. After obtaining chi square test value, $p$ value was ascertained and the value of $<0.05$ was interpreted as significant.

\section{Results}

125 patients (mean age, $32 \pm 7.7$ years old; $52 \%$ males) were investigated. The mean duration of infection was
$5.4 \pm 3.2$ years. Medical history indicated taking antituberculosis medication (25\%) and constant use of antibiotics (40\%), anti-fungal therapy (4\%) and highly active antiretroviral therapy (HAART, 44\%).

Absolute CD4 counts were categorized in four different groups: Group I ( $>500$ cells $\left./ \mathrm{mm}^{3}\right)$, Group II (350-499 cells $\left./ \mathrm{mm}^{3}\right)$, Group III (200-349 cells $\left./ \mathrm{mm}^{3}\right)$ and Group IV $\left(0-200\right.$ cells $\left./ \mathrm{mm}^{3}\right)$. Out of the 125 cases studied, it was observed that 60 patients $(52 \%)$ of the cases exhibited periodontal disease which was highest prevalence of the oral lesions followed by erythematous candidiasis (48\%). The pseudomembranous form of candidiasis was seen in $12 \%$ of the cases (Table 2 ).

As the immunosuppression worsened the oral manifestations increased (Table 3). In groups 1-3 the most prevalent manifestation was erythematous candidiasis (chi square -24.528 and $\mathrm{p}<0.001$ ) whereas the trend shifted to periodontal disease in group 4 (chi square - $38.624 p<0.001$ ) (Table 4). 19 cases of oral hairy leukoplakia were reported, out of which 11 were found in the severely immunosuppressed Group IV (Table 3).

89 out of total 125 cases showed the presence of lesion, one lesion was observed in 23 patients, 2 in 19 ,

Table 2. Prevalence of Oral lesions in HIV positive patients.

\begin{tabular}{lcc}
\hline \multicolumn{1}{c}{ Prevalence of Oral Lesion } & $\mathbf{n}$ & Percentage (\%) \\
\hline Erythematous candidiasis & 60 & 48.0 \\
\hline Hyperpigmentation & 41 & 32.8 \\
\hline Oral hairy leukoplakia & 19 & 15.2 \\
\hline Linear gingival erythema & 21 & 16.8 \\
\hline Periodontal disease & 65 & 52.0 \\
\hline Angular chelitis & 16 & 12.8 \\
$\begin{array}{l}\text { Pesudomembranous } \\
\text { candidiasis }\end{array}$ & 15 & 12.0 \\
\hline
\end{tabular}

Table 3. Prevalence of intraoral lesions in different groups of HIV- WHO Classification of immunosuppression.

\begin{tabular}{|c|c|c|c|c|c|}
\hline Lesion & $\mathbf{n}$ & $\begin{array}{l}\text { Not significant } \\
\text { >500 CD4 count }\end{array}$ & $\begin{array}{c}\text { Mild } \\
\text { 351-500 CD4 count }\end{array}$ & $\begin{array}{c}\text { Advanced } \\
\text { 200-349 CD4 count }\end{array}$ & $\begin{array}{c}\text { Severe } \\
<200 \text { CD4 count }\end{array}$ \\
\hline Erythematous candidiasis & 60 & 05 & 09 & 16 & 30 \\
\hline Hyperpigmentation & 41 & 04 & 08 & 11 & 18 \\
\hline Oral hairy leukoplakia & 19 & 01 & 03 & 05 & 11 \\
\hline Linear gingival erythema & 21 & 02 & 04 & 06 & 09 \\
\hline Periodontal disease & 65 & 03 & 07 & 15 & 40 \\
\hline Angular chelitis & 16 & 01 & 04 & 06 & 05 \\
\hline Pseudomembranous candidiasis & 15 & 01 & 03 & 05 & 06 \\
\hline
\end{tabular}


Table 4. Chi square test performed to find relation between intraoral lesions and increase in immunosuppression in HIV positive population.

\begin{tabular}{lcr}
\hline Lesion & Chi square test & P value \\
\hline Erythematous Candidiasis & 24.528 & $<0.001$ \\
Hyperpigmentation & 17.949 & $<0.001$ \\
\hline Oral hairy leukoplakia & 14.347 & $<0.001$ \\
\hline Linear gingival erythema & 13.323 & $<0.001$ \\
\hline Periodontal disease & 38.624 & $<0.001$ \\
\hline Angular chelitis & 7.162 & 0.007 \\
$\begin{array}{l}\text { Pseudomembranous } \\
\text { candidiasis }\end{array}$ & 10.254 & 0.001 \\
\hline
\end{tabular}

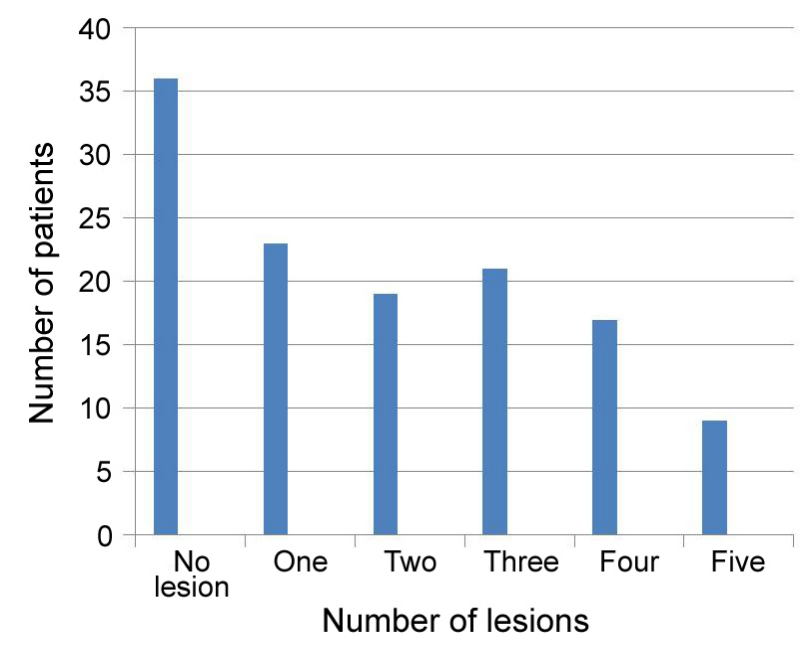

3 lesions in 21 cases, 4 in 17 patients and 5 lesions in 9 cases (Figure 1).

There was an evident increase in number of lesion and decreased average CD4 count with increased level of immunosuppression (Figure 2).

\section{Discussion}

Various studies have noted different prevalence of oral lesions due to variable sample size, degree of immunosuppression, inter-examiner differences, and regional patterns of infectious diseases. Therefore, extrapolating the results comparing the reported prevalence of existing studies may not be useful.

This study had almost equal gender distribution with $52 \%$ males which is in contrast to the studies done by Sharma et al. (13], Nittayananta et al. [17] ,Ranganathan et al. [16] where males were predominant.

The study was done in the age group of 20-40 years as this age range shows the peak distribution of people affected with HIV.

The present study noted an overall prevalence of oral lesions of $71 \%$ in the HIV infected population of Dakshina Kannada regardless of the severity of the disease which is lower when compared to previous studies done by Sharma et al. [13], and Ranganathan [18]. This may be due to the fact that in the current study higher number of patients was on highly active antiretroviral therapy (HAART).

Figure 1. Number of patients with multiple lesions.

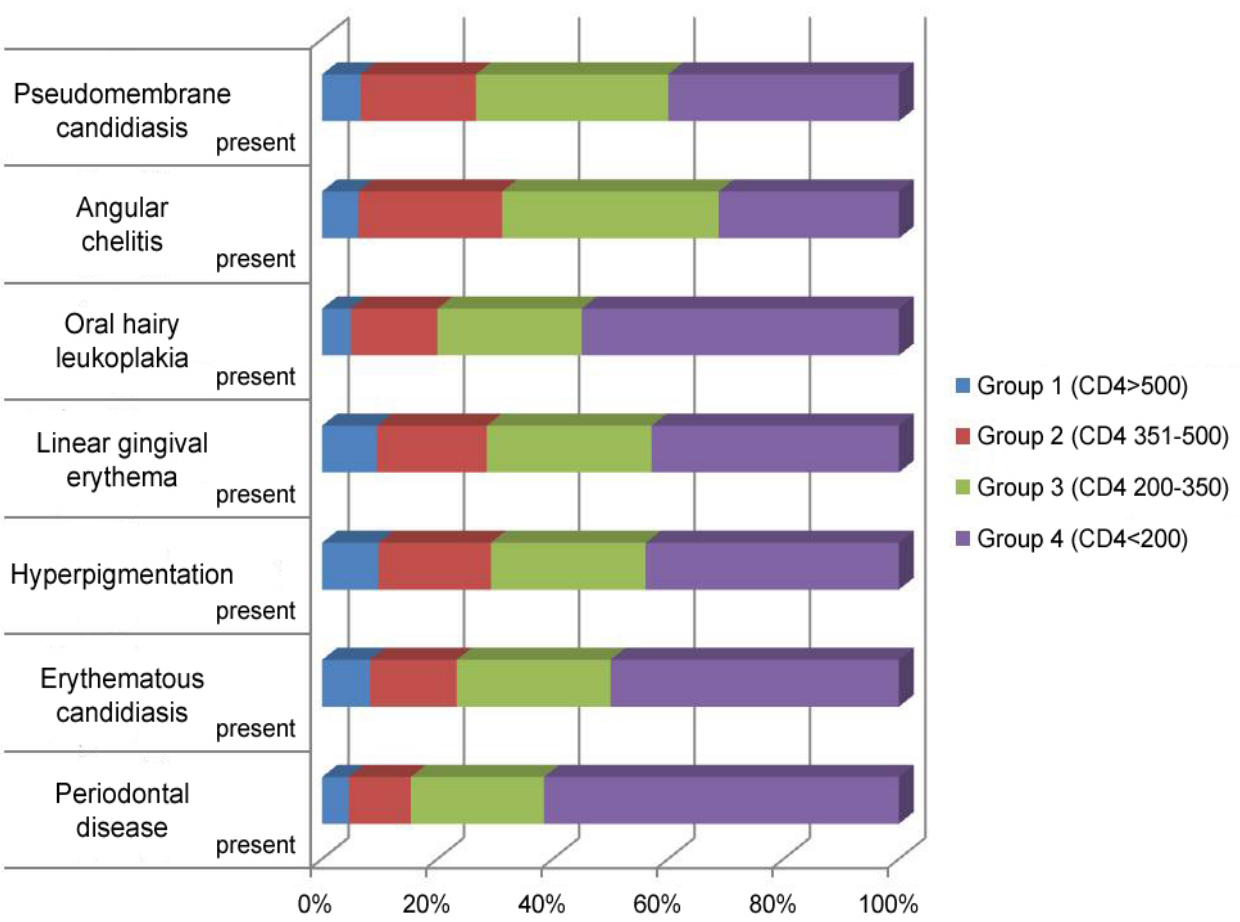

Figure 2. Oral lesions increase with the increase of immunosuppression (decrease of CD4 count). 
Periodontal disease showed the highest prevalence $(52 \%)$, which was not noted in the previous studies; this may be a result of poor oral hygiene, drugs, medications. Periodontitis showed highly significant relationship with the increase in immunosuppression.

Oral candidiasis was the common finding with Erythematous candidiasis showing prevalence in $48 \%$ of the patients which is in agreement with a previous study done in the same region by Sharma and colleagues [12].

The prevalence of oral lesions viz. hyperpigmentation $(32.8 \%)$, linear gingival erythema $(16.8 \%)$, hairy leukoplakia (15.2\%), angular cheilitis (12.8\%), and pseudomembranous candidiasis $(12 \%)$ was found to be consistent with the previous studies [12-14].

With new research studies, the treatment modalities instituted have increased the lifespan of people infected with HIV. Yengopal et al. in 2007 found that Oral lesions associated with HIV infection negatively affect the oral health-related quality of life in infected patients [15]. Thus, the dentist has an important role to play along with the medicine specialist in monitoring the progression of the disease.

A significant relation was found between oral lesions and the degree of immunosuppression ( $p$ value $<0.001$ ).

\section{REFERENCES}

1. Bajpai S, Pazare AR . Oral manifestations of HIV. Contemp Clin Dent 2010; 1 (1): 1-5.

2. Little J, Falace D, Miller C, Rhodus NL. Dental Management of the Medically Compromised Patients, 6th ed. Laxington: Mosby; 2003; 221-222.

3. Pedreira EN, Cardoso CL, Barroso Edo C, Santos JA, Fonseca FP, Taveira LA. Epidemiological and oral manifestations of HIV positive patients in a specialized service in Brazil. $J$ Appl Oral Sci 2008; 16: 369-375.

4. Santos LC, Castro GF, De Souza IP, Oliveira RH. Oral manifestations related to immunosuppression degree in HIV positive children. Braz Dent $J$ 2001; 12: 135-138.

5. Flaitz CM, Hicks MJ. Oral candidiasis in children with immune suppression: clinical appearance and therapeutic considerations. ASDC J Dent Child 1999; 66: 161-6,154.

6. 6. Taiwo OO, Okeke EN, Jalo PH, Danfillo IS. Oral manifestation of HIV/AIDS in Plateau state indigenes, Nigeria West. Afr J Med 2006; 25: 32-37.

7. Sud N, Shanker V, Sharma A, Sharma NL, Gupta M. Mucocutaneous manifestations in $150 \mathrm{HIV}$ - infected Indian patients and their relationship with CD4 lymphocyte counts. Int J STD AIDS 2009; 20: 771-774.

8. Nokta M. Oral manifestations associated with HIV infection. Curr HIV/AIDS Rep 2008;5: 5-12.

9. EEC Clearinghouse on oral problems related to HIV infection and WHO Collaborating Center on oral manifestations of the Human Immunodeficiency Virus. Classification and diagnostic criteria for oral lesions in HIV infection. J Oral Pathol Med 1993; 22: 289-291

10. World Health Organization WHO case definitions of HIV for surveillance and revised clinical staging and immunological
The number of lesions increased with increased degree of immunosuppression as has been pointed out by the study done by Sharma et al. [12]. The oral lesions were studied according to the immunosuppression staging done by WHO in 2007 so that the preventive measures instituted for the oral health can be correlated to the WHO treatment guidelines in different stages of infection. This may also have implications on diagnosis and prognosis of the disease [10].

The periodontal disease and oral hairy leukoplakia increased sharply in the severely immunosuppressed stage of HIV disease and can be useful in predicting the progression of the disease.

Even though, there is an increase in awareness, prevention and extensive treatment strategies due to the programmes carried out by WHO in developing countries, the decrease in oral lesions is not significant hence studies testing the methods of improving oral hygiene and in turn oral health needs to be carried out.

\section{Acknowledgement}

The authors would like to acknowledge Indian Council of Medical Research, New Delhi, India, ART centre, Wenlock Hospital and Nitte University, Mangalore. classification of HIV - related disease in adults and children. World Health Organization, Geneva: 1-52

11. Adurogbangba MI, Aderinokun GA, Odaibo GN, Olaleye OD, Lawoyin TO. Oro-facial lesions and CD4 counts associated with HIV/AIDS in an adult population in Oyo State, Nigeria. Oral Dis. 2004; 10: 319-326.

12. Sharma. G, Pai. KL, Shetty. S, Ramapuram JT, Nagpal A. Oral manifestations as predictors of immune suppression in a HIV-AIDS infected population in South India. Clin Oral Invest. 2009; 13: 141-148

13. Sharma G, Pai KM, Suhas S, Ramapuram JT, Doshi D, Anup N. Oral manifestations in HIV / AIDS infected patients from India. Oral Dis. 2006 ; 12: 537-542

14. Soares MSM, Leite DFBM, Arnaud RR, Filho FDCO, Lima AMH, De Sousa DS et al. Oral Lesions and systemic diseases in HIV - infected subjects. J. Infect. Dis. Immun. 2011; 3: 172-175

15. Yengopal V, Naidoo S. Do oral lesions associated with HIV affect quality of life? Oral Surg Oral Med Oral Pathol Oral Radiol Endod 2008; 106: 66-73

16. K Ranganathan, M Umadevi, TR Saraswathi, N Kumaraswamy, S Solomon, N Johnson. Oral lesions and conditions associated with Human Immunodeficiency Virus infection. Ann Acad Med Singapore 2004; 33(Suppl): 37S-42S.

17. Nittayananta W, Chungpanich S. Oral lesions in a group of Thai people with AIDS. Oral Diseases 1997; 3 (Suppl 1): 41-56.

18. Ranganathan K, Reddy BVR, Kumarasamy N, Solomom S, Viswanathan R, Johnson NW. Oral lesions and conditions associated with human immunodeficiency virus infection in 300 south Indian patients. Oral Diseases 2000; 6: 152-157. 